UDC 821.133.1.05(091)

DOI https://doi.org/10.32841/2409-1154.2020.44.18

Vysotska R.R.,

Enseignante du département des langues étrangères de l'Université nationale Polytechnique de Lviv

Zalutska H. I.,

Enseignante du département des langues étrangères de l'Université nationale Polytechnique de Lviv

\title{
DON JUAN DE MOLIERE, PERSONNAGE A SUCCES DE LA TRAGI-COMEDIE CLASSIQUE FRANCAISE AU XVII-IÈME SIECLE
}

\begin{abstract}
Summary. The article has been devoted, first of all, to the question of the analysis of the term of tragicomedy in French classicistic literature. Particular attention has been paid to the characteristics of the comic character in the play. A detailed analysis of the structure of the work has been carried out. Special attention has been focused on the system of secondary, noble and sacred characters. We have presented the examples of conversion of places and characters into symbols. Molière came to literature during the day of the classicist tragedy. Comedies were seen by viewers as a frivolous spectacle that only entertained the audience. Moliere provided comedy with a completely different content. His plays were not only entertaining but also instructive. Taking images and situations from his modern life, the play showed people their flaws, passions and mistakes. Molière combined the rules of classicism with the traditions of folk theater, which gave his works a special vitality those of dynamism. They became a manifestation of the very spirit of the people, the spirit of free thinking, disobedience, and protest against everything false and vicious. Molière proved that comedy can affect the viewer no less, and perhaps even more than tragedy. At the same time, the artist was a true innovator in the field of literature and theatrical activity, because he went beyond classicism and established new principles of dramaturgy."Don Juan, or the Stone Guest" ("Don Juan, ou Le Festin de Pierre"), written in 1665, during the persecution of Tartuffe. Looking for a way out, Molière picked up a theme that has been repeatedly developed in French, Italian and Spanish theaters. Moliere transformed the Seville Caballero into a Fratus nobleman. For the first time, there has been an image in the literature that cannot be evaluated unequivocally.Don Juan is the embodiment of depravity, cynicism, spiritual annoyance, immorality, but there are also positive qualities in him - reason, courage, free-thinking, common sense. However, the play again exposes the priesthood and hypocrisy: Don Juan becomes a kind of complement to Tartuffe's image. At the same time, the artist affirms the versatility of human nature. Molière modifies the theme of Don Juan. Don Juan is not so much a violator of social norms, but an embodiment of the negative sides of those norms. The viciousness of his behavior is only a peculiar manifestation of the viciousness of the ruling circles. But Moliere made Don Juan not only the bearer of the vices of old society, but also the representative of new ideas. More precisely, not so much the ideas of the third state as the preachers of the negative attitude towards all the norms adopted by the old society, which had to be
\end{abstract}

developed as a result of the viciousness of the old regime. Don Juan's materialism and rationalism served to dismantle old masks and promote new values. In all of this lies the deeply humanistic nature of the comedy Moliere.

Key words: master, human being, vocation, art of Molière, research, farce, play.

La farce est cette petite pièce comique, d'une centaine de vers ou de lignes seulement, qui a trouvé son succès populaire au XVième et au XVI ième siècle, en faisant rire par tous les moyens : comique de mot, de situation, de geste. Dom Juan, pièce grave et parfois douloureuse, peut sembler aux antipodes de la farce. Pourtant, cette pièce s'inscrit encore dans cet héritage par deux aspects [1, p.106].

La définition du problème. Ensuite, la pièce touche au comique de farce par l'évocation crue des choses du corps et de l'argent. C'est Sganarelle qui est le porte-parole comique de ces questions d'intendance, lui qui, d'un bout à l'autre de la pièce, n'a de préoccupations que matérielles: éloge paradoxal du tabac au début et demande incongrue de ses "gages" à la fin de la pièce. L'acte III nous montre un personnage dont le raisonnement "a le nez cassé" alors qu'il essaie de s'élever vers l'abstraction (III, 1) ou qui invoque une excuse scatologique (le "purgatif") pour justifier la lâcheté de sa fuite (III, 5) [1, p.120]. Notre objectif de recherche est de désigner par "le terme comédie" une conception de la littérature selon laquelle l'écrivain doit chercher non pas à réaliser le réel, mais au contraire à le représenter fidèlement. Cette définition est cependant peu satisfaisante car elle convient à un très grand nombre d'oeuvres écrites à des époques totalement différentes et ne peut donc conduire à une études intéressante qui représente l'actualité du travail.

Le matériel de base. La comédie de Molière s'inspire des modèles antérieurs. Elle reprend des éléments de la comedia espagnole, comédie romanesque, qui s'organise en "journées" (et qui se distribue en tableaux, dans des espaces successifs). La comedia fait intervenir tous les milieux sociaux, des aristocrates au peuple le Dom Juan de Molière également. Un personnage comme Sganarelle doit beaucoup au gracioso ou valet bouffon de la comédie espagnole [2, p. 159]. La comedia ne cherche pas exclusivement à être drôle mais intègre des scènes d'action : enlèvements, combats, duels, affrontements, et produit des effets dramatiques et pathétiques. ElIe relève d'une esthétique baroque en ce qu'elle interroge le réel et l'imaginaire: elle présente, par là, 
une visée morale et religieuse, la réflexion sur l'au-delà. Dans Dom Juan, la Statue du Commandeur renvoie aux lois divines et à la nécessité de s'y soumettre.

A côté de cette influence espagnole, il faut noter l'imprégnation de la commedia dell'arte, comédie italienne, largement improvisée et destinée à faire rire: les lazzi (ou mots d'esprit), les gesticulations de Sganarelle, ses volte-face subites sont aussi marqués par les mouvements bouffons de la comédie d'inspiration italienne et populaire. Le petit genre de la pastorale a eu son succès en France dans la première moitié du XVIIe siècle, où il correspondait à un divertissernent de cour. Il met en scène une intrigue amoureuse dans une nature de convention [2, p. 168]. Tout l'acte II de Dom Juan détourne l'univers idyllique de la pastorale, entre bergers et bergères. Molière reprend ces amours dans un paysage naturel pour leur donner des accents plus franchement comiques.

La suite de la pièce relève davantage d'un autre genre, pros gressivement éclipsé à son tour, la tragi-comédie. La tragi-comédie est une pièce en cinq actes, en vers, mettant en scène des aventures nombreuses dans un univers noble : amours, rencontres, combats, tout semble placé sous le signe du hasard. Les pérégrinations et les rencontres dans la forêt à l'acte III, puis la venue de Dom Louis, le père de Dom Juan, à la scène 4 de l'acte IV, ont des accents de tragicomédie. L'entre, vue avec Dom Louis semble même inspirée par des modèles de père noble cornélien, avec le ton solennel d'usage et les sentences frappées dans des alexandrins blancs : "La naissance n'est rien où la vertu n'est pas." [4, p. 96]. Mais en proposant un siège, le personnage de Dom Juan - et Molière avec lui - fait retomber la scène dans la trivialité de la franche comédie.

Molière fait ainsi de Dom Juan une comédie singulière: en cinq actes mais en prose. L'auteur sacrifie aussi à un goût de son époque, celui des machines - la statue qui bouge, qui marche, qui parle, les feux de Bengale, le bruitage tonitruant etla trappe qui s'ouvre à la fin. Molière hérite donc d'une tradition et s'en démarque. "Il met bien en scène des personnages de condition morale inférieure" critère de la comédie - en particulier un grand seigneur vicieux et un valet bouffon. Mais le personnage répréhensible ne fait aucunement rire, contrairement à ce qui se passe dans ses autres comédies: Arnolphe, Orgon et même Tartuffe étaient par moments très comiques. "La pièce adopte bien aussi un niveau de - language moyen" et des paroles diverses, et vise la correction des vices des hommes ici le libertinage et ses dégâts. Cependant, ce n'est pas, le héros vicieux qui est ridicule, mais son double bouffon, Sganarelle, qui doit, de surcroit, représenter la voix de la piété et du bon sens. Le message moral s'en trouve brouillé. Il n'est plus sûr que Dom Juan corrige vraiment le vice "par rire" [3, p. 176].

Il est bien difficile de définir un "registre" dans Dom Juan. Cela tient au langage différent de chaque personnage: Sganarelle et les paysans sont le plus souvent dans la tonalité comique, Done Elvire apporte une note pathétique et parfois lyrique, Dom Louis et les frères d'Elvire parlent un langage tragicomique, Dom Juan dessine sans cesse un contrepoint ironique; et la Statue du Commandeur donne à la pièce une dimension à la limite du tragique et du fantastique.

Il en résulte un changement constant de style: éloquence faussement didactique et tonalité héroï-comique - traitement décalé d'un sujet bas - chez Sganarelle (I,1); revirements burlesques du valet et éloquence ironique de Dom Juan (I, 2; II, 5, III, 1; IV, 5; V, 2); pathétique d'Elvire et ironie de Dom Juan (I, 3); comique de mots des paysans et scène émouvante de dépit amoureux (II, 1); jeu ironique de la séduction et comique de mots avec les paysannes (II, 2 et II, 4); comique de geste soufflets - et pathétique de la situation de Pierrot (II, 3); pathétique du Pauvre et ironie de Dom Juan (III, 2); commentaires de tragi-comédie sur le duel, l'honneur, et ironie sourde de Dom Juan (III, 3; III, 4; V, 3); comique de mots et de situation avec M, Dimanche (IV, 2; IV, 3); éloquence tragique de Dom Louis et réponse ironique de Dom Juan (IV, 4); accents pathétiques et lyriques de Done Elvire et commentaires ironiques de Dom Juan (IV, 6); accents pathétiques et joyeux de Dom Louis, et lyrisme ironique de Dom Juan (V, 1); traitement burlesque, mais aussi tragique et fantastique, des confrontations avec le surnaturel et en particulier avec la Statue du Commandeur (III, 4; IV, 7; IV, 8; $\mathrm{V}, 4 ; \mathrm{V}, 5 ; \mathrm{V}, 6)$. Le héros n'a pas prise sur l'action, et la subit de manière apparemment désordonnée et arbitraire. On peut moins parler ici d'une "unité d'action que d'une unité de péril" (les dangers croissants courus par le héros). Contrairement à la tradition de la comédie, l'intrigue contrariée n'est pas un mariage puisque ce mariage a déjà eu lieu et qu'il est bafoué [6, p. 96]. Au nom de l'unité de péril - un héros de plus en plus menacé chaque acte semble engager une nouvelle intrigue: recherche par Dom Juan d'une nouvelle proie (acte 1), improvisation devant les paysannes (acte II), rencontres fortuites au fond d'une forêt (acte III), retour pressant des obligations passées (acte IV), jeu extrême de l'hypocrisie et châtiment final (acte V). L'action se passe, en principe, "en Sicile". C'est la seule indication de lieu explicite. La géographie italienne est démentie cependant par le nom et par le langage de bien des personnages. M. Dimanche, le créancier de l'acte IV, a un nom bien français, comme les paysans de l'acte II, à commencer par Pierrot, dont la parole emprunte largement au patois d'île-de-France. Le nom du grand personnage féminin qu'invente Molière, Elvire, appartient clairement à la dramaturgie française (Da Ponte et Mozart la transformeront en Elvira comme ils feront passer l'espagnol "Don Juan" dans l'italien "Don Giovanni"). On ne trouvera guère de consonances italiennes, puisque les autres personnages ont plutôt des noms espagnols (Dom Juan, Dom Louis, Dom Carlos...).

Pas plus qu'il n'y a de couleur locale italienne, il n'y a d'unité de lieu dans la pièce. L'ancienne unité de lieu était celle d'une ville et de ses environs. Molière en joue très librement dans Dom Juan [7, p. 100]. L'édition même du texte ne fixe pas l'endroit précis de l'action, mais on peut le déduire du dialogue et se référer aussi aux premières éditions "cartonnées" de la pièce, qui tenaient compte des représentations (d'où les indications en note pour les actes II, III, IV et V, marquant, chaque fois, un changement de lieu). À chaque acte correspond en effet un espace différent; on peut même considérer qu'il y a six décors distincts dans la pièce puisqu'un changement à vue intervient au cours de l'acte III : on passe d'un paysage extérieur à l'intérieur du mausolée où se trouve la Statue du Commandeur. On est donc très loin de l'unité rigoureuse de lieu qui imposerait à l'action un espace, et un seul. Et cette diversité d'endroits dit la mobilité physique et affective, 1 "inconstance" structurelle du héros. On passe aussi d'un espace neutre de rencontre, les abords ou l'entrée d'un palais au premier acte, à un espace sauvage et solennel, plongé dans l'ombre, la forêt et le mausolée du dernier acte [9, p. 36]. Dans Dom Juan, on glisse ainsi d'un cadre diurne (acte I et II) à un cadre nocturne (forêt et lieux clos ou sombres des trois derniers ans), soit d'un paysage de vie à un paysage de mort. Pas plus qu'il n'y a d'unité d'action et d'unité d'espace, il n'y d'unité de temps au sens strict dans Dom Juan. 
La règle des vingt-quatre heures n'y est pas observée. L'action s'étend au moins sur deux journées. À la scène 8 de l'acte IV, la Statue invite le héros à dîner le lendemain - et l'on sait la Statue très ponctuelle lorsqu'on la retrouve à la fin de l'acte suivant. Et même, de l'acte I à l'acte IV, si c'est une seule journée qui s'écoule, elle serait remplie de tant d'événements qu'elle en paraîtrait invraisemblable. De fait, la seule "vraisemblance" temporelle est celle de la durée de la représentation. Le temps perçu par le spectateur pendant chaque acte doit coïncider avec celui de la représentation de chaque scène et le temps ne peut s'accélérer qu'entre les actes. D'où les quelques ellipses, entre l'acte I et l'acte II. Le héros occupe donc presque toute la comédie qui porte son nom (il n'est absent que dans deux premières scènes de présentation, au début de l'acte I et de l'acte II). On suit le parcours d'un être à la fois désirant et traqué.

Le personnage se définit par son statut social prestigieux, entaché par son vice annoncé par Sganarelle: "un grand seigneur méchant homme". C'est un noble qui abuse de son pouvoir non seulement sur les femmes qu'il rencontre, mais aussi sur son valet. Personnage qui s'arroge les privilèges de sa caste, l'impunité présumée, mais qui ne reconnaît aucun de ses devoirs. Son père le lui reproche au nom des lois familiales, morales et humaines. Dom Juan reste simplement fidèle aux coutumes guerrières de sa caste et à ce code de l'honneur qui le pousse à accepter l'affrontement, dans un combat inégal à l'épée, à l'acte III, ou même face au surnaturel qu'il a défié, dans les dernières scènes.

"Son vice" est la recherche effrénée de la séduction des femmesle "donjuanisme" vient de là [8, p. 21]. Le héros use, à cet effet, de toutes les ressources de la parole: virtuose de l'improvisation et du langage efficace, il sait déployer tous les trésors de l'éloquence, de la conversation, mais aussi faire parler les autres ou les réduire au silence. En ce sens, il apparaît aussi comme l'image même du comédien ou de l'ironiste - l'ironie est son registre de prédilection au sens étymologique du mot. Il met en question toutes les autres paroles, et par là amène à se demander quelle parole il faut prendre au sérieux.

Aristocrate dévoyé et danger public, séducteur et virtuose ironique de l'improvisation, le personnage est placé sous le sceau de l'ambiguité, puisqu'il est condamnable et condamné sans être ridicule $[7$, p. 28]. Le personnage, surtout, ne se réduit pas à sa caractéristique connue: les conquêtes féminines. Le libertin Dom Juan n'a d'existence que par son aspect d'incrédule et de profanateur. Il est celui qui transgresse non seulement les lois humaines mais aussi les lois divines, puisqu'il s'en prend ouvertement au Ciel en défiant le sacré. Le personnage prend sens par rapport au temps, à la mort et à l'au-delà. Il est celui qui parie sur la vie présente, qui refuse toute possibilité de salut après la mort. Et c'est le fondement même du mythe auquel il a donné lieu. L'a mbiguité de Dom Juan tient à la résistance qui lui est opposée par son valet. Il n'est guère possible de montrer au XVII siècle un valet supérieur à son maître [6, p. 206]. Et pourtant, c'est ce valet, Sganarelle, qui est le dépositaire des valeurs plus recommandables de la raison, de la religion et de la morale. Sganarelle joue dès lors un rôle complexe dans la pièce, d'autant qu'il est presque tout le temps présent (tout comme son maître, il n'est absent que dans deux scènes) et qu'il a déjà un passé dans d'autres pièces de Molière - d'homme du peuple, drôle, grossier, qui cherche à s'élever par un savoir incertain. Dans Dom Juan, il assure d'abord la fonction d'auxiliaire du héros - il doit le servir malgré lui dans ses entreprises -,de confident et de porte-parole - il doit donner la réplique à son maitre (I, 2; III, 1; IV, 5; V, 2), et parfois s'exprimer en son nom, devant Elvire ou la Statue (I, 3; III, 5; IV, 8). Il assure simultanément l'emploi du valet comique et constitue un contrepoint bouffon, par son langage ridicule, ses appétits ou ses revirements très lâches. Il a pour fonction théâtrale de faire rire.

Il s'agit enfin de la Statue du Commandeur. Contrairement à la tradition, Molière n'en fait pas le père tué d'une femme séduite (Anna), et le personnage, un peu mystérieux et arbitraire, surgit tardivement dans la pièce, à la fin de l'acte III. Cette utilisation d'une "machine" - statue qui bouge et qui parle - met la mort en scène, marque les grandes étapes attendues, le défi lancé à la Statue, l'invitation et la contre-invitation, l'entrainement en enfer.

Le premier fait preuve d'élégance, d'honnêteté, de lucidité aussi face aux faux-fuyants de Dom Juan, le second plus intransigent, paraît enfermé dans les codes aristocratiques d'autrefois et défend l'urgence du quel pour venger sa soeur.

Quelques personnages, plus épisodiques encore, ont un petit rôle dramatique et assurent aussi une détente comique dans la pièce. C'est le cas de Pierrot, sauveur de Dom Juan, et battu par son bienfaiteur ingrat et rival sans pitié [7, p. 106]. Le patois grossier du personnage, son amour sincère pour Charlotte l'injustice de sa situation inspirent pourtant de la compassion. Autour de lui, deux paysannes naïves, Charlotte et Mathurine, également éblouies par la cour de Dom Juan, permettent au séducteur de se montrer en action au deuxième acte auprès d'une caste sociale qui lui est inférieure, preuve que toutes les femmes l'intéressent, quel que soit leur milieu. Le dédoublement des paysannes favorise une situation comique de difficulté et de double langage (II, 4). "C'est une autre naïveté, celle de la bourgeoisie fascinée par la noblesse - quitte à se faire spolier qu'incarne le créancier M. Dimanche au début de l'acte IV, preuve que la séduction de Dom Juan n'opère pas qu'auprès des femmes. On n'aurait garde enfin d'oublier quelques utilités", personnages fugitifs qui ne servent que Paction et le dialogue : le personnage muet de Gusman, auprès duquel Sganarelle a tout loisir de briller ridiculement dans la première scène; La Ramée, qui assure le rôle du messager à la fin de l'acte II; La Violette, qui annonce les arrivées au début de l'acte V; Ragotin, qui assure le service et l'intendance à la fin de l'acte IV. Ces personnages pittoresques, même lorsqu'ils ne parlent guère, redonnent tous ses droits à la comédie [7, p. 110].

Pour conclure. Dom Juan est un joueur - celui qui parie contre le Ciel, pour les plaisirs de la terre. Il fait partie de ces libertins à qui Pascal, dans ses Pensées, entend montrer qu'ils ont fait le mauvais pari, qu'ils ne peuvent que tout perdre. Le sujet est important. Mais la pièce disparait vite dans l'affiche. Humiliation posthume: cette pièce est remplacée par une version affadie, une transcription en vers réalisée par Thomas Corneille en 1677 pour la Comédie Française [8, p. 87]. Dom Juan meurt foudroyé au XVIIe siècle; la pièce aussi, après quinze représentations. Mais depuis le milieu du XXe siècle, la comédie et son héros sont revenus plus vivants que jamais sur la scène du théâtre.

\section{Liste des ouvrages consultés:}

1. Bricka B. Molière. Panorama d'un auteur 10. Levallois-Perret : Jeunes Éditions - Studyrama, $2003.156 \mathrm{p}$.

2. Dodeller S. Molière. Belles vies. Paris : L'école des loisirs, 2005. $189 \mathrm{p}$.

3. Faguet E. "Molière". Dans Dix-septième siècle : Etudes littéraires. Nouvelle bibliothèque littéraire. Paris : Ancienne librairie Furne, Boivin, 2009. 294 p.

4. Hutier J.-B. Dom Juan : Molière : 12 sujets corrigé. Profil littérature. Oral de français 168. Paris : Hatier, 1994. 205 p. 
5. Ker W. P. "Molière and the Muse of Comedy". Dans The Art of Poetry : Seven Lectures. Oxford : Clarendon Press, 1923. 245 p.

6. Leplâtre O. Étude sur Molière : Dom Juan. Résonances. Paris : Ellipses-Marketing, 1998. 306 p.

7. Rojat P-H. Dom Juan: Molière. L'œuvre au clair 11. Paris : Bordas, 2003. 159 p.

8. Rolland J. Le petit Molière ou La naissance à la gloire d'un jeune prodige du théatre : Michel Baron. Illustré par Xavier Christin. Paris : P. Téqui, $1999.366 \mathrm{p}$.

9. Simon A. Molière par lui-même. Écrivains de toujours 40. [Paris] : Éditions du Seuil, 1957. 289 p.

Висоцька Р. Р., Залуцька Г. І. Дон Жуан Мольєра, успішний персонаж французької класицистичної трагікомедії 17-го століття

Анотація. Представлена робота присвячена насамперед питанню аналізу терміну трагікомедії у французькій літературі епохи класицизму. Особлива увага у п’єсі приділяється характеристикам комічного персонажа. Здійснено детальний аналіз структури роботи. Окрема увага зосереджена на системі другорядних, благородних та сакральних персонажів. Ми представили приклади перетворення місць та персонажів на символи. Мольєр прийшов у літературу в період розквіту класицистичної трагедії. Комедії сприймалися глядачами як несерйозне видовище, що мало лише розважати публіку. Мольєр надав комедії зовсім іншого змісту. Його п'єси були не тільки цікавими, а й повчальними. Беручи образи і ситуації із сучасного йому життя, драматург показував людям їхні вади, пристрасті й помилки. Мольєр поєднав правила класицизму 3 традиціями народного театру, що надало його творам особливої життєвості ті динамізму. Вони стали виявом самого духу народу, духу вільнодумства, непокори та протесту проти всього ницого, фальшивого, порочного. Мольєр довів, що комедія може впливати на глядача не менше, а, можливо, навіть і більше, ніж трагедія. Водночас митець був справжнім новатором у галузі літератури й театральної діяльності, бо вийшов за межі класицизму й заклав нові принципи драматургії. «Дон Жуан, або Кам'яний гість» ("Don Juan, ou Le Festin de Pierre"), написаний в 1665 році, в період гонінь на «Тартюфа». Шукаючи вихід, Мольєр узяв тему, яка неодноразово розроблялася у французькому, італійському та іспанському театрах. Мольєр перетворив севільського кабальєро на фрацузького шляхтича. Уперше в літературі з'явився образ, котрий не можна оцінити однозначно. Дон Жуан - втілення розбещеності, цинізму, духовної ницості, аморальності, але при цьому в ньому є і позитивні якості розум, сміливість, вільнодумство, здоровий глузд. Мольєр поставив собі за мету дати критику розпусного суспільства, яке породжує таких героїв, як Дон Жуан. Разом 3 тим драматург знову викриває святенництво і лицемірство: Дон Жуан стає своєрідним доповненням образу Тартюфа. Водночас митець утверджує багатогранність людської натури. «Зображуючи сильні і слабкі сторони особистості, він закликав повернутися до моральних законів у житті людства». Мольєр змінює та поглиблює тему Дон Жуана. Дон Жуан не стільки порушник суспільних норм, скільки втілення негативних сторін цих норм. Сама порочність його поведінки являється лише своєрідним виявленням порочності правлячих кіл. Але Мольєр зробив Дон Жуана не тільки носієм пороків старого суспільства, але й представником нових ідей. Точніше кажучи, «не стільки ідей третього стану, скільки проповідників того негативного відношення до всіх прийнятих старим суспільством норм, яке повинне було виробитися в результаті усвідомлення порочності старого режиму». Матеріалізм та раціоналізм Дон Жуана слугували зриванню старих масок та утвердженню нових цінностей. У всьому цьому полягає глибоко гуманістичний характер комедії Мольєра.

Ключові слова: господар, людина, покликання, мистецтво Мольєра, фарс, гра. 